\title{
Insucesso na amamentação do prematuro: alegações da equipe
}

\section{Unsuccess in breastfeeding premature newborns: allegations of the profesional staff}

\author{
Roberta Tognollo Borotta Uema ${ }^{1}$; Mauren Teresa Grubisich Mendes Tacla²; \\ Adriana Valongo Zani ${ }^{3}$; Sarah Nancy Deggau Hegeto de Souza ${ }^{4}$; Edilaine \\ Giovanini Rossetto ${ }^{5}$; Juliana Cristina Trevisan Santos ${ }^{6}$
}

\begin{abstract}
Resumo
Apesar dos diversos métodos empregados pelos profissionais da unidade de terapia intensiva neonatal para estimular o aleitamento materno do prematuro, em alguns casos a lactação não é bem sucedida. Observou-se que o tempo e os esforços desprendidos neste processo geram um sentimento de frustração não somente nas mães, mas também na equipe de saúde. Este trabalho buscou desvelar as experiências de profissionais de saúde de uma Unidade de Terapia Intensiva Neonatal frente a situações de insucesso na amamentação do recém-nascido prétermo. Trata-se de uma pesquisa de abordagem qualitativa mediante entrevistas individuais com os profissionais de uma Unidade de Terapia Intensiva Neonatal de hospital escola público, Londrina-PR, em 2012. Empregouse um roteiro semiestruturado, cujas falas dos entrevistados foram transcritas e analisadas seguindo Análise de Conteúdo. A partir desse processo, foram identificadas quatro categorias: Frustração advinda do insucesso do processo de aleitamento materno; Sentimento de "dever cumprido"; Fatores maternos influenciando o desfecho da amamentação: opinião dos profissionais; Fatores físicos e externos influenciando negativamente no processo da amamentação. Alguns profissionais afirmaram ter superado rapidamente o sentimento de frustração, enquanto outros ainda se ressentiam sobre o ocorrido e questionavam suas próprias habilidades. A cooperação materna com a equipe e a existência de um ambiente mais propício à amamentação foi considerada determinante no resultado. Enquanto pesquisadoras não foi possível interferir na infraestrutura, porém sugerimos a realização de reuniões para discussões sobre amamentação com familiares e profissionais, bem como grupos de ordenha com as mães para manutenção da produção láctea.
\end{abstract}

Palavras-chave: Prematuro. Aleitamento materno. Unidades de terapia intensiva neonatal. Equipe de assistência ao paciente. Enfermagem Neonatal

\begin{abstract}
In spite of the many methods used by the Neonatal Intensive Care Unit workers to stimulate the breastfeeding of premature babies, some cases are unsuccessful. It was noticed that both time and effort spent in this process may generate a feeling of frustration not only to the mothers, but also to the health care professionals. This research aims to reveal experiences lived by the health care staff in situations of unsuccessful breastfeeding of preterm newborns. Following a semi-structured script, staff members of the Neonatal Intensive Care Unit of the school public hospital, Londrina-PR, in 2012. Their quotes were transcribed and analyzed according to the Content Analysis method. Four categories were identified through the previous process: Frustration arising from the
\end{abstract}

\footnotetext{
${ }^{1}$ Enfermeira. Especialista em Enfermagem Neonatal. Mestranda pelo programa de pós-graduação em Enfermagem da Universidade Estadual de Maringá.

${ }^{2}$ Enfermeira. Professor Adjunto do Departamento de Enfermagem, Área Saúde da Criança e do Adolescente. Universidade Estadual de Londrina.

${ }^{3}$ Enfermeira. Professor Adjunto do Departamento de Enfermagem, Área Saúde da Criança e do Adolescente. Residência em Enfermagem Neonatal. Centro de Ciências da Saúde.

${ }^{4}$ Enfermeira. Doutora em Ciências. Professor Adjunto do Departamento de Enfermagem da Universidade Estadual de Londrina.

${ }^{5}$ Enfermeira. Professor Adjunto do Departamento de Enfermagem, Área Saúde da Criança e do Adolescente. Universidade Estadual de Londrina.

${ }^{6}$ Acadêmica do curso de graduação em Enfermagem na Universidade Estadual de Londrina.
} 
failure of the process of breastfeeding; Feeling of "duties fulfilled"; Maternal factors influencing the outcome of breastfeeding: the professionals' opinion; Physical and external factors influencing negatively the process of breastfeeding. While some workers deal easily with the negative outcome, some resent the unsuccessful process for a while and question their own abilities. Maternal cooperation with the staff and the existence of an environment more conducive to breastfeeding were considered in determining outcome. As researchers, we can not act on the infrastructure, but we suggest holding meetings for discussions about breastfeeding families and professionals, and groups of milking mothers to maintain milk production.

Keywords: Premature. Breastfeeding. Neonatal intensive care units. Patient care team. Neonatal Nursing

\section{Introdução}

Os benefícios do aleitamento materno exclusivo (AME) durante os primeiros meses de vida da criança são conhecidos há muito tempo e, frequentemente, novas pesquisas reforçam sua importância (WOORDWARD; LIBERTY, 2011). A importância do aleitamento materno já foi comprovada por meio de diversos estudos científicos e atualmente são vários os argumentos que atuam em seu favor. Segundo o Ministério da Saúde (BRASIL, 2009), os benefícios do leite materno vão desde a proteção contra diarreias e problemas respiratórios até diminuição dos índices de mortalidade infantil.

A prática do aleitamento materno ainda ajuda a desenvolver a cavidade bucal, protege as mulheres contra o câncer de mama, ajuda a evitar uma nova gravidez não planejada, apresenta baixíssimos custos financeiros, além de promover o vínculo mãe-bebê contribuindo para uma melhor qualidade de vida de ambos (BRASIL, 2009). O Ministério da Saúde preconiza a amamentação exclusiva até o sexto mês de vida do bebê, não havendo necessidade de complementação com chás, sucos e água para recém-nascidos a termo e quando possível para recém-nascidos pré-termo (RNPT) (BRASIL, 2011).

O aleitamento materno também exerce alta influência na redução da mortalidade dos lactentes, uma vez que devido à suas características próprias $\mathrm{e}$ pelos anticorpos e fatores anti-infecciosos contidos no leite materno, torna-se importante para o sistema imunológico, além de ser facilmente digerido, facilitando a eliminação meconial e diminuindo o risco de icterícia neonatal. Quando comparado ao leite de vaca ou a fórmula infantil, ele ainda previne alergias, é mais facilmente digerido e rico em ômega-3, importante no desenvolvimento do sistema nervoso central (ODDY, 2013).

O colostro, também chamado de "primeiro leite", oferece inúmeras citocinas em um momento importante para o organismo imaturo dos recémnascidos, que necessitam desses componentes para um desenvolvimento adequado, e a falta ou o funcionamento inadequado desses componentes nos sistemas imunes inatos do intestino e do leite, podem propiciar o desenvolvimento de doenças entéricas no recém-nascido (ODDY, 2013).

Apesar dos benefícios do leite materno, a amamentação do RNPT ainda é um desafio em muitos aspectos, pois o parto abrupto e fora do tempo esperado traz consigo diversos sentimentos e expectativas, além de alterar a rotina e dinâmica familiar. Estudos revelam que nessas situações surgem emoções ambivalentes, principalmente devido à vulnerabilidade biológica do recémnascido, pois de um lado existe a alegria pelo nascimento do filho, epelo outro existem sentimentos de sofrimento, frustração e culpa pela fragilidade do bebê (ANJOS et al., 2012). Somam-se a isso os longos períodos de internação do bebê e muitas vezes a falta de apoio à família, principalmente à mãe, no manejo adequado da lactação.

Em algumas situações, o hospital não é um ambiente confortável e estimulante para a ordenha materna, e a mãe não possui recursos financeiros para o transporte diário até a unidade de internação 
neonatal, para oferta de leite fresco e entrega de leite ordenhado para pasteurização. Infelizmente nesses casos a mamadeira e a sonda orogástrica acabam sendo prescritos como uma alternativa mais fácil, embora estudos comprovem que o aleitamento artificial interfira na formação da arcada dentária e nas funções de deglutição, mastigação e sucção (CALADO; SOUZA, 2012).

O processo de amamentação dos filhos, enquanto estão internados em unidade de terapia intensiva, merece atenção especial dos profissionais de saúde sendo estes os grandes responsáveis pelo posterior sucesso da prática (SILVA; MENDES; ARRUDA, 2014). Sendo assim, o objetivo deste estudo foi desvelar as experiências de profissionais de saúde de uma Unidade de Terapia Intensiva Neonatal (UTIN) frente a situações de insucesso na amamentação do recém-nascido pré-termo.

\section{Material e Métodos}

Trata-se de um estudo descritivo de abordagem qualitativa, cujos participantes foram membros da equipe de saúde que atuam na UTIN de um hospital universitário do município de LondrinaPR. A amostra foi constituída por 10 sujeitos, sendo estes uma fonoaudióloga, uma residente médica de pediatria, três enfermeiras, quatro auxiliares e uma técnica de enfermagem. O número de sujeitos não foi pré-determinado e prosseguiu-se com a realização das entrevistas até que o objetivo do estudo fosse alcançado. Todos os sujeitos foram instruídos previamente sobre o objetivo da pesquisa, seu sigilo na participação da mesma e assinaram o Termo de Consentimento Livre e Esclarecido (TCLE).

As entrevistas foram realizadas no próprio ambiente de trabalho, com auxílio de um roteiro semiestruturado, testado previamente com uma entrevista-piloto. As perguntas norteadoras foram: "Conte uma experiência de insucesso na amamentação de prematuro na UTIN", "A que fatores você atribui este evento?" e "Que sentimentos esta situação despertou em você?”.

As falas foram gravadas, posteriormente transcritas e receberam um código para preservar o anonimato dos sujeitos. A análise foi realizada por meio da análise teórica de conteúdo de Bardin (2011), a qual consiste em: $1^{\circ}$ ) Pré-análise: fase de organização dos dados brutos, cujo objetivo é sistematizar as ideias iniciais por meio de leituras flutuantes para estabelecer contato com os documentos. Tem como regras principais a exaustividade, representatividade, homogeneidade e pertinência; $2^{\circ}$ ) Exploração do material e formação de categoriais: classificação dos dados por diferenciação, e em seguida, reagrupamento segundo critério semântico, para obtenção das categorias temáticas; $3^{\circ}$ ) Tratamento das categorias obtidas e interpretação: seleção das categorias significativas juntamente com as inferências e a opinião de outros autores.

O estudo foi aprovado pelo Comitê de Ética em Pesquisa Envolvendo Seres Humanos da Universidade Estadual de Londrina (CEP/ UEL), parecer $\mathrm{n}^{\circ}$ 042/2012, CAAE $\mathrm{n}^{\circ}$ 01463512.8.0000.5231e atendeu aos princípios da Resolução no 466, de 12 de dezembro de 2012 (BRASIL, 2012).

\section{Resultados}

O tempo de atuação em UTIN entre os profissionais entrevistados variou entre um a vinte anos, sendo os profissionais de enfermagem àqueles com maior permanência na unidade. A segunda profissional que está há mais tempo na unidade foi a fonoaudióloga, seguida da residente médica de pediatria.

Após leitura e análise dos relatos, formaramse quatro categorias: Frustração advinda do insucesso do processo de aleitamento materno; Sentimento de "dever cumprido"; Fatores maternos influenciando o desfecho da amamentação: opinião 
dos profissionais; Fatores físicos e externos influenciando negativamente no processo da amamentação.

\section{Frustração advinda do insucesso do processo de aleitamento materno}

A fala dos profissionais reflete uma situação muitas vezes cotidiana dentro da UTIN. O processo de estabelecimento da amamentação do prematuro se inicia logo após o nascimento, momento no qual a mãe é abordada e instruída a realizar a ordenha manual e a armazenar o leite de maneira adequada para enviar a seu bebê internado. Quando o bebê passa por todas as intercorrências advindas da internação, tanto a mãe como a equipe estão ansiosos para iniciar o aleitamento materno e torcem pelo sucesso da prática.

$\mathrm{Na}$ medida em que este se torna difícil e nos casos em que ele não é bem sucedido, e por estarem próximos da mãe e acompanharem todo o processo, sentimentos de frustração e incapacidade, além do questionamento sobre o próprio trabalho podem surgir entre os profissionais.

[...] ela era uma mãe já perto dos quarenta, não era uma mãe jovenzinha, era uma mulher mais experiente, madura e ela sabia o que ela queria. E ai ela não conseguiu realizar isso e é chato. A gente fica triste $[\ldots]$. (P1)

[...] Ah, eu fico bastante chateada, extremamente. Às vezes fico tão chateada que não durmo direito [...] na verdade é todo o contexto que tem, a gente sai um pouco triste por não ter resolvido isso [...] A gente fica triste quando retorna e diz que "ai, não mamou"... a gente sabe que o aleitamento materno é o mais importante [...]. (P7)

[...] a gente se sente assim, será que foi algo que nós não fizemos e que deveria ter feito? [...] é um insucesso da gente [...]. (P3)

\section{Sentimento de "dever cumprido"}

Alguns membros da equipe referiram que aprenderam a lidar melhor com o sentimento de frustração e compreenderam que nem sempre o sucesso ocorre em $100 \%$ dos casos, assim como todos os processos vitais. Podemos perceber pelas falas que os profissionais estão aparentemente bem resolvidos com a situação, pois entenderam que trabalharam ativamente e que se a situação não apresentou um desfecho favorável não foi devido à falta de esforços.

[...] a gente tem que colocar na cabeça que nós estamos lidando com um prematuro, que são situações diferenciadas e que a gente vai ter o insucesso presente na nossa vida. É lógico que não é o que a gente deseja, mas a gente acaba tendo que conviver com ele [...]. (P10)

[...]Ah, fica triste... fica para próxima [...] Mas a gente sabe que $100 \%$ a gente não consegue mais. Então eu também não vou ficar estressada por causa disso, porque a gente tentou. Se não deu certo... nós fizemos a nossa parte. Agora, a gente sabe que nem tudo a gente consegue. Porque senão fica só desesperada e não dá certo [...]. (P6)

Fatores maternos identificados que influenciam no desfecho da amamentação: opinião dos profissionais

Nessa categoria, identificamos que embora fatores como alterações anatômicas maternas e dificuldades promotoras do neonato tenham sido consideradas, o motivo mais apontado para que o aleitamento não fosse estabelecido foi a própria opção da mãe em não amamentar, juntamente com a imaturidade materna e a própria hospitalização do bebê.

Tem umas que amam amamentar, dão o peito com prazer, mas tem mães que você vê que não quer mesmo, não adianta. Elas podem até ficar tentando dar aqui para o nenê ter alta e ir embora. Mas você vê que é dela mesmo, ela não quer e não aceita; não adianta ficar batendo em cima. Ela não aceita, ela não vai ter condições [...]. (P9)

[...] a amamentação a mãe tem que querer, porque se não querer não adianta, viu [...] a gente conversa, fala [...] sobre todo o aleitamento materno... mas [...] elas não querendo não tem jeito, é meio complicado $[\ldots]$... (P3)

[...] Você prepara a mãe pro aleitamento e a mãe às vezes [...] é muito nova, então ela não tem aquela responsabilidade de amamentar, de fazer ordenha $[\ldots]$ mas ao mesmo tempo, tem avó que não estimula em casa, se é menor de idade [...] 
tem muitas avós [...] que foi daquele tempo de mamadeira então não estimula e aquelas mães muito jovem não tem aquele compromisso [...]. (P2)

[...]Tem mães que ficam três meses, então às vezes também por estar internado na UTI elas ficam nervosas. Tem mãe que você dá notícia ruim todo dia, a criança piora, isso elas não conseguem produzir leite, elas não conseguem tirar. Tem inclusive uma agora que em casa ela consegue, aqui ela não consegue porque fica muito nervosa e saber que o bebê está na UTI... acho que pela gravidade do bebê elas ficam cansadas, ficam o dia inteiro aqui. [...]. (P8)

Fatores físicos e externos influenciando negativamente no processo da amamentação

Os profissionais referem que a falta de infraestrutura da unidade neonatal é em parte responsável pelo insucesso do aleitamento materno. As internações acima do número de vagas, a falta de acomodações e a dificuldade materna em conseguir chegar e permanecer na unidade também foram apontados como fatores decisivos.

[...] Tem a superlotação. Hoje, por exemplo, a gente quer ensinar as mães e não tem estrutura, às vezes não tem nem banco para nós sentar para ajudar as mães. Que o bebê tem de ficar lá um tempão, você entendeu? Não tem funcionária [...]. (P7)

[...] É difícil para elas virem aqui, não tem espaço direito, elas ficam nervosas... não é fácil, não [...]. (P6)

[...] Eu acho que tinha que ter um espaço melhor para elas [as mães] também, elas ficam aqui o dia inteiro, não tem nenhuma cadeira, nenhuma poltrona mais confortável, um lugar de descanso... às vezes elas vem de longe, vem de ônibus... tudo isso assim piora. [...]. (P8)

\section{Discussão}

Em relação à temática Frustração advinda do insucesso do processo de aleitamento materno percebe-se que geralmente quando o bebê começa a sugar o seio materno já superou várias dificuldades durante a internação e não se espera que a amamentação seja mais uma delas, fato que pode justificar a frustração apresentada pelos profissionais de saúde quando esta não ocorre como se espera. $\mathrm{O}$ sentimento de culpa além de interferir na jornada de trabalho repercute também na vida pessoal, pois um dos entrevistados relatou que não conseguia dormir direito frente a tal situação e outro questionou sua própria capacidade enquanto profissional.

Amamentar ainda é um desafio. Depende das condições de vida, do momento vivido pela mulher, de suas experiências anteriores, sua cultura e também da própria compreensão da sociedade, portanto, ajudar a mulher a estabelecer e manter essa prática é uma tarefa bastante complexa (FUJIMORI et al., 2010).

O fato do profissional ter colocado em questão sua habilidade em ajudar o binômio enquanto cuidador atuante dentro da unidade é algo que deve ser trabalhado e melhorado. O sentimento de frustração não é benéfico em nenhuma situação, principalmente em se tratando do estabelecimento do aleitamento materno, evento que indica que a alta hospitalar do bebê está próxima. Valorizar os profissionais que atuam diretamente na assistência ao bebê prematuro contribui de maneira significativa no desenvolvimento da sua autoestima enquanto funcionário cuidador daquele recém-nascido.

No que tange ao Sentimento de "dever cumprido" pode-se observar pelos relatos, que por trabalharem em um ambiente inconstante e passível de mudanças a todo o momento como é característico da unidade de terapia intensiva, os profissionais desenvolveram mecanismos para lidar melhor com as dificuldades que surgem no dia-a-dia, incluindo o desfecho negativo no processo de amamentação. Por um lado, isso se torna um ponto positivo, pois é difícil alcançar tal grau de maturidade e segurança no próprio trabalho, por outro pode ser preocupante, pois não se sabe ao certo se essa postura não é apenas um mecanismo de defesa para esconder sua real percepção frente a esta vivência.

O ambiente hospitalar não é totalmente favorável à amamentação em muitos aspectos, 
mas quando existe o desejo e a força de vontade em amamentar, essas dificuldades podem ser superadas com estímulo de bons profissionais que acreditam no binômio mãe-bebê. É bom que os profissionais tenham essa postura bem resolvida, porém vale lembrar que essa postura não pode ser confundida com a falta de vontade em tentar. Em alguns casos, por já terem experiências negativas anteriores os profissionais podem simplesmente desistir da prática temendo um desfecho negativo e por acreditarem que já sabe qual será o desfecho daquela situação.

A falta de capacitação e habilidade dos profissionais responsáveis por ações referentes ao aleitamento materno pode propiciar o desmame precoce e favorecer o aumento da taxa de mortalidade infantil. Em um hospital universitário, as orientações e informações sobre o manejo da amamentação devem ser rotineiras, pois além de contribuir para a formação dos próprios profissionais que atuam na área, faz com que estes sejam constantemente atualizados a respeito do tema e desenvolvam novas maneiras de agir em determinada situação (MAGALHÃES; RODRIGUES, 2014).

A temática fatores maternos identificados que influenciam no desfecho da amamentação: opinião dos profissionais identificou que as mães de prematuros passam por um turbilhão de emoções. O nascimento precoce, as diversas intercorrências durante a internação, a dificuldade em se conseguir o peso adequado para a alta hospitalar, somado a insegurança em como se adaptar com o bebê em casa faz com que muitas mães fiquem confusas em relação ao aleitamento materno. Muitas vezes, o estresse gerado durante a amamentação não é suportável frente a todos os problemas já vividos e estas acabam por adotar outra opção para alimentar seu bebê.

Amamentar bebês prematuros é um desafio não apenas pela imaturidade fisiológica e controle inadequado da sucção/deglutição/respiração.
Soma-se a isso a insegurança materna em lidar com bebês tão frágeis e delicados o que pode ajudar na conclusão de que elas não se sentem capazes de amamentá-los naquele momento. Além disso, a percepção de que seu bebê não é nada igual àquele que uma vez ela idealizou, pode fazer com que a mãe demore um pouco para aceitar essa nova realidade (GORGULHO; PACHECO, 2008).

Quando pensamos nas mães adolescentes a situação se torna mais complexa. A dificuldade em aceitar a gravidez, a mudança na rotina, em alguns casos deixar de frequentar a escola, o compromisso em realizar a ordenha manual de três em três horas e a falta de apoio familiar, faz com que essas meninas desistam do aleitamento por não perceberem a importância deste na vida de seu filho e não encontram apoio em mães e avós mais experientes e que poderiam auxiliá-las nesse processo.

Neste contexto, porém não somente relacionado às mães adolescentes, os profissionais devem dar atenção especial à ordenha manual. Independente da vivência prévia de cada mãe, a equipe de saúde deve estar preparada para ensinar a técnica correta e garantir que todas as mães aprendam a tirar seu próprio leite, saibam armazená-lo e se sintam estimuladas a realizar ordenha na própria unidade para oferecer o leite fresco ao bebê (GORGULHO; PACHECO, 2008). O compromisso em saber que de alguma maneira ela está alimentando seu filho é fundamental para o sucesso da lactação

Os relatos dos profissionais são bastante verdadeiros e refletem uma realidade infelizmente, comum. O sucesso do aleitamento materno começa ainda no acompanhamento pré-natal, onde aparecem as primeiras orientações a cerca do tema. Para que haja sucesso na amamentação é preciso articular práticas desde a gestação, para que durante a hospitalização a mãe se sinta estimulada em manter a produção láctea, e posteriormente a alta continuar recebendo apoio 
e acompanhamento pela atenção básica a fim de auxiliar no cuidado com o bebê e no aleitamento.

Em decorrência de dificuldades na estrutura física da unidade surgiu à temática Fatores físicos e externos influenciando negativamente no processo da amamentação, pois durante o período de coleta dos dados a unidade passava por um momento delicado, uma vez que ocupava um espaço físico provisório e bastante debilitado, enquanto o setor novo estava em reforma. Infelizmente, é comum a unidade estar com mais bebês internados do que o preconizado, em virtude do pequeno número de vagas, entretanto, o número de funcionários permanece o mesmo, apesar do número de bebês internados ser maior.

Estudo realizado por Maciel, Almeida e Braga (2014) demonstram que as dificuldades referidas pelas mães corroboram com as situações colocadas pelos profissionais em nossa pesquisa. Segundo as mães, o ambiente hospitalar, é desfavorável à prática da amamentação por ser um local impessoal, apresentar rotinas e horários pré-estabelecidos.

$\mathrm{Na}$ perspectiva dos profissionais, a criação de um ambiente tranquilo e mais acolhedor para o momento do aleitamento materno seria um estímulo às mães, principalmente para as que residem longe do hospital, em cidades vizinhas e que dependem de ônibus para visitar seus filhos.

Nesse momento funcionários de outras unidades, e alguns sem experiência em neonatologia, foram remanejados de outros setores para ajudarem a prestar assistência aos pacientes. Todos esses fatores dificultam uma assistência de qualidade quando falamos do aleitamento materno, prática em que é necessário ter experiência e paciência para ouvir a mãe, estar atenta aos sinais do bebê, e entender que uma sucção eficaz não ocorre do dia para a noite. É preciso tempo, estímulo, lançar mão de técnicas como a translactação para obter um resultado positivo.

\section{Conclusão}

Mesmo com a utilização de vários métodos disponíveis e dos esforços na orientação e estímulo do aleitamento materno, o profissional de saúde da UTIN convive diariamente com a possibilidade do insucesso. Alguns membros da equipe experimentam um sentimento de frustração que pode persistir por muito tempo após o evento, e questionam seus conhecimentos e sua capacidade profissional.

A equipe alega que o desinteresse e o despreparo emocional de algumas mães estão dentre os fatores que podem interferir no processo da amamentação. Os sujeitos deste estudo reconhecem que as delicadas circunstâncias da internação do prematuro abalam o equilíbrio psicológico materno, mas apontam que muitas vezes a opção em não amamentar parte da própria mãe e que sem a colaboração desta, o trabalho da equipe sozinha acaba sendo em vão.

A responsabilização materna pelo insucesso da prática precisa ser melhor pesquisada, discutida e explorada com a equipe, pois a literatura aponta inúmeros fatores que interferem no sucesso da amamentação, não apenas a decisão da mãe, incluindo influências culturais, experiências anteriores, medos e incertezas, além de dificuldades dentro do ambiente familiar.

O presente estudo permitiu obter maior compreensão sobre as dificuldades encontradas pelos funcionários da UTIN na vivência do processo da amamentação do prematuro, tanto no âmbito emocional da equipe, quanto dos fatores apontados como responsáveis pelo seu insucesso. Durante a construção deste trabalho, verificou-se a existência de poucos estudos sobre os sentimentos dos profissionais em relação ao aleitamento materno do bebê prematuro. A maioria das pesquisas foca a mãe e, quando questiona o profissional, evidencia seus sentimentos de modo geral e não especificamente relacionados à amamentação, área de grande atuação da equipe de saúde dentro deste setor.

Apesar dos problemas físicos e estruturais da unidade refletir diretamente naqueles que estão 
prestando assistência aos bebês e suas famílias, isso acaba sendo algo que não compete ao profissional que está envolvido no cuidado. É sabido que já ocorreram e ainda ocorrem reivindicações em prol da melhoria estrutural da unidade, porém, em se tratando de um hospital público o repasse de recursos não é tão rápido e efetivo como deveria.

Infelizmente, enquanto pesquisadoras não têm muito a fazer nesse âmbito, porém sugerimos que além da realização de novos estudos envolvendo a temática, sejam realizados grupos de apoio tanto para mães e familiares dos bebês internados, como para a própria equipe, para que estes últimos sejam estimulados a expor suas dificuldades sobre a amamentação, sanar dúvidas que possam aparecer nesse processo e até mesmo capacitá-los sobre técnicas alternativas de ofertar leite humano ao RNPT, como a translactação, que além de estimular o aumento da produção láctea, evita a confusão de bicos causada pela oferta de leite por copo ou chucas e mamadeiras.

Especificamente com as mães, sugerimos algo já realizado na unidade estudada e que surtiu um efeito bastante positivo. Trata-se de um grupo de ordenha, no qual todas as mães que estavam presentes na unidade naquele momento, eram estimuladas a ordenhar seu leite tanto para ser ofertado fresco para o bebê no horário preestabelecido da dieta, como para ser encaminhado ao Banco de Leite Humano para pasteurização e posterior envio à UTIN. Este era um momento no qual as mães dividiam experiências, compartilhavam sentimentos e ainda conseguiam auxiliar na manutenção da sua produção láctea.

Destacamos também a importância de se realizar o trabalho em prol da amamentação envolvendo a equipe multiprofissional. É preciso estar atento e lembrar que os maiores beneficiados no sucesso do aleitamento materno são mãe e bebê e que os profissionais devem estar conscientes do seu papel neste processo. Os que atuam na área neonatal são capacitados para tal função e devem empenhar-se para fazer aquilo que é melhor para o binômio. Dessa forma, quando ocorrer insucesso na amamentação, provavelmente a frustração sentida pelo profissional será menor, pois ele terá a certeza de que se empenhou para que não fosse esse o desfecho.

\section{Referências}

ANJOS, L. S.; LEMOS, D. M.; ANTUNES, L. A.; ANDRADE, J. M. O.; NASCIMENTO, W. D. M.; CALDEIRA, A. P. Percepções maternas sobre o nascimento de um filho prematuro e cuidados após a alta. Revista Brasileira de Enfermagem, Brasília, v. 65, n. 4, p. 571-577, jul/ago. 2012. Disponível em: $<$ http://www.scielo.br/pdf/reben/v65n4/a04v65n4. pdf $>$. Acesso em: 21 jul. 2014.

BARDIN, L. Análise de conteúdo. Lisboa: Edições 70, 2011. $280 \mathrm{p}$.

BRASIL. Ministério da Saúde. Secretaria de Atenção à Saúde. Departamento de Atenção Básica. Saúde da criança: nutrição infantil. Brasília, 2009. Disponível em: <http://bvsms.saude.gov.br/bvs/ publicacoes/saude_crianca_nutricao_aleitamento_ alimentacao.pdf $>$ Acesso em: 21 jul. 2014.

- Departamento de Ações Programáticas e Estratégicas. Atenção à saúde do recém-nascido: guia para os profissionais de saúde. Cuidados com o recém-nascido pré-termo. Brasília: Ministério da Saúde, 2011. Disponível em: <http://bvsms. saude.gov.br/bvs/publicacoes/atencao_recem nascido_\%20guia_profissionais_saude_v4.pdf $>$. Acesso em: 21 jul. 2014.

. Conselho Nacional de Saúde, Comissão Nacional de Ética em Pesquisa. Resolução $n^{\circ} 466$ de 12 de dezembro de 2012: diretrizes e normas regulamentadoras de pesquisas envolvendo seres humanos. Brasília, 2012. Disponível em: <http:// bvsms.saude.gov.br/bvs/saudelegis/ cns/2013/ res0466_12_12_2012.html>. Acesso em: 21 jul. 2014. 
CALADO, D. F. B; SOUZA, R. Intervenção fonoaudiológica em recém-nascido pré-termo: estimulação oromotora e sucção não-nutritiva. Revista CEFAC, São Paulo, v. 14, n. 1, p. 176-181, jan./fev. 2012. Disponível em: $<$ http://www.scielo.br/pdf/rcefac/ v14n1/194-09.pdf>. Acesso em: 21 jul. 2014.

FUJIMORI, E.; NAKAMURA, E.; GOMES, M. M.; JESUS, L. A.; REZENDE, M. A. Aspectos relacionados ao estabelecimento e à manutenção do aleitamento materno exclusivo na perspectiva de mulheres atendidas em uma unidade básica de saúde. Interface, Botucatu, v. 14, n. 33, abr.jun. 2010. Disponível em: <http://www. scielo.br/pdf/icse/v14n33/a07v14n33.pdf>. Acesso em: 27 jul. 2014.

GORGULHO, F. R.; PACHECO, S. T.A. Amamentação de prematuros em uma unidade neonatal: vivência materna. Revista da Escola de Enfermagem Anna Nery, Rio de Janeiro, v. 12, n. 1, 2008. Disponível em: <http:// www.scielo.br/pdf/ean/v12n1/v12n1a03.pdf $>$. Acesso em: 27 jul. 2014.

MACIEL, I. V. L; ALMEIDA, C. S; BRAGA, P. P. O aleitamento no contexto da prematuridade: o discurso materno. Revista de Enfermagem da UFPE, Recife, v. 8, n. 5, maio 2014. Disponível em: $<$ http://www.revista. ufpe.br/revistaenfermagem/index.php/revista/article/ view/4772/pdf_5028>. Acesso em: 27 jul. 2014.

MAGAlHÃES, C. P.; RODRIGUES, A. M. Conhecimento de profissionais de saúde sobre aleitamento materno em um Hospital Universitário do Vale do Paraíba (SP). Revista de Ciências Humanas, Taubaté, v. 7, n. 1, 2014. Disponível em: <http://www. rchunitau.com.br/index.php/rch/article/view/123/71>. Acesso em: 27 jul. 2014.

ODDY, H. W. Aleitamento materno na primeira hora de vida protege contra mortalidade neonatal. Jornal de Pediatria, Porto Alegre, v. 89, n. 2, p. 109-111, mar./abr. 2013. Disponível em: <http://www.scielo.br/pdf/jped/ v89n2/v89n2a01.pdf $>$. Acesso em: 21 jul. 2014.

SILVA, M. A. M; MENDES, E. M.; ARRUDA, L. D. Aleitamento materno de recém-nascidos hospitalizados: grupo de apoio desenvolvido junto a puérperas adolescentes. Revista Adolescência e Saúde. Rio de Janeiro, v. 11, n. 1, p. 44-51, jan./mar. 2014. Disponível em: $<\mathrm{http}$ ://adolescenciaesaude.com/audiencia_pdf.as p?aid2 $=435 \&$ nomeArquivo $=v 11$ 1n1a07.pdf $>$. Acesso em: 21 jul. 2014.
WOORDWARD, L. J.; LIBERTY, K. A. O aleitamento materno e o desenvolvimento psicossocial da criança. In: TREMBLAY, R. E.; BOIVIN, M.; PETERS, R. D. V. (Ed.). Enciclopédia sobre o desenvolvimento na primeira infância. Montreal, Quebec: Centre of Excellence for Early Childhood Development, 2011. p. 1-7. Disponível em: $<$ http://www.enciclopedia-crianca. com/documents/Woodward-LibertyPRTxp1.pdf $>$. Acesso em: 21 jul. 2014.
Recebido em: 30 jul. 2014. Aceito em: 18 nov. 2014. 
